\title{
Sutureless valve and rapid deployment valves: a systematic review and meta-analysis of comparative studies
}

\author{
Campbell D. Flynn ${ }^{1,2}$, Michael L. Williams ${ }^{2,3,4,5}$, Adam Chakos ${ }^{2,6}$, Lucy Hirst ${ }^{2}$, Benjamin Muston ${ }^{2}$, \\ David H. Tian ${ }^{2,7,8}$
}

${ }^{1}$ Department of Cardiothoracic Surgery, Epworth Hospital, Richmond, Melbourne, Australia; ${ }^{2}$ The Collaborative Research (CORE) Group, Macquarie University, Sydney, Australia; ${ }^{3}$ Department of Cardiothoracic Surgery, Royal Prince Alfred Hospital, Sydney, Australia; ${ }^{4}$ The Baird Institute of Applied Heart \& Lung Surgical Research, Sydney, Australia; ${ }^{5}$ University of Sydney, Sydney, Australia; ${ }^{6}$ Faculty of Medicine and Health Sciences, Macquarie University, Sydney, Australia; ${ }^{7}$ Department of Anaesthesia and Perioperative Medicine, Westmead Hospital, Sydney, Australia; ${ }^{8}$ Chris O’Brien Lifehouse, Sydney, New South Wales, Australia

Correspondence to: Campbell D. Flynn. Department of Cardiothoracic Surgery, Epworth Hospital, Richmond, Melbourne, Australia.

Email: campbellf@doctors.org.uk.

Background: The treatment of aortic valve disease is the most common valvular surgery in industrialized nations, with 3-9\% of the population over the age of eighty having at least moderate aortic stenosis. As transcatheter aortic valve replacement (TAVR) has become more established, newer surgical prostheses have been developed with a variety of anchoring systems that do not rely solely on sutures to hold the valve in an appropriate position. The Edwards Intuity valve is a bovine pericardial prosthesis that is modelled on the widely implanted Perimount MagnaEase aortic prosthesis. The Perceval valve is a bovine pericardial valve attached to a self-expanding nitinol stent, which uses the radial force exerted on the patient's aortic annulus and aortic root by the stent portion to hold the valve in position. This meta-analysis compares the outcomes of comparative studies of these two valve systems.

Methods: This systematic review and meta-analysis compares the outcomes of rapid deployment valves (RDV) and sutureless valves (SURD) and was performed in accordance with the Preferred Reporting Items for Systematic Reviews and Meta-Analyses (PRISMA) recommendations and guidance. The search strategy interrogated six electronic databases. Outcomes measured included all-cause mortality at latest follow up, stroke, cross-clamp and cardiopulmonary bypass (CPB) times, pacemaker implantation rates, paravalvular leak and post-operative transvalvular gradient.

Results: The search strategy identified 407 unique papers for initial assessment with seven studies qualifying for inclusion in the analysis. The outcomes of 4,076 patients (1,650 RDV, 2,426 SURD) were included. There was no difference in mortality, stroke or moderate or worse paravalvular regurgitation between the two groups. SURD had significantly shorter CPB time by 15.7 minutes [95\% confidence interval (CI): 4.2-27.1; $\mathrm{P}=0.007]$ and a shorter cross-clamp time by 11.3 minutes (95\% CI: 6.3-16.3; $\mathrm{P}<0.001$ ) compared to RDV. RDV had a lower post-operative transvalvular gradient by $2.5 \mathrm{mmHg}(95 \% \mathrm{CI}: 1.2-3.8 ; \mathrm{P}<0.001)$ and a lower rate of mild paravalvular regurgitation (OR 2.51; 95\% CI: 1.435-4.768; P=0.004).

Conclusions: Both valve types have an adequate safety profile and are comparable to conventional sutured prostheses. There was a significant reduction in cross-clamp and CPB times associated with SURD. This may be of benefit for patients requiring multiple concomitant procedures and increases the utility of minimally invasive valve replacement. However, SURD was associated with higher post-operative transvalvular gradients and a higher incidence of paravalvular regurgitation.

Keywords: Rapid deployment valve (RDV); sutureless valve; aortic valve replacement

Submitted Jul 18, 2020. Accepted for publication Aug 28, 2020.

doi: 10.21037/acs-2020-surd-27

View this article at: http://dx.doi.org/10.21037/acs-2020-surd-27 


\section{Introduction}

The treatment of aortic valve disease is the most common valvular surgery in industrialized nations (1), with $3-9 \%$ of the population having at least moderate aortic stenosis over the age of 80 (2). Historically, surgical valve replacement has been the gold standard procedure. However, the treatment of aortic valve pathology has been in a state of flux for the last two decades with an increase in the use of transcatheter aortic valve replacement (TAVR) in low-risk patients (3). As TAVR has become more established, newer surgical prostheses have been developed with a variety of anchoring systems that do not rely solely on sutures to hold the valve in the appropriate location. Three solutions were eventually brought to market: the 3F Enable prosthesis (ATS Medical, Inc, Minneapolis, MN, USA), the Perceval valve (Perceval, Livanova PLC, London, UK) and the Intuity valve (Intuity, Edwards Lifesciences, Irvine, CA, USA).

The $3 \mathrm{~F}$ Enable valve is comprised of a self-expanding, nitinol-stented prosthesis that is secured to the surgically debrided aortic annulus with two sutures. After development, this valve solution suffered several valve dislodgements and has been subsequently removed from the market. The Edwards Intuity valve is a bovine pericardial prosthesis that is modelled on the widely implanted Perimount MagnaEase aortic prosthesis and has been modified to include a balloon expandable sub-annular skirt that prevents paravalvular regurgitation after the valve is deployed. Three sutures that are equally spaced around the surgically debrided aortic annulus secure the valve, thus it is described as a rapid deployment valve (RDV). The Perceval valve is a bovine pericardial valve attached to a selfexpanding nitinol stent. It is initially guided into position using three sutures, which are subsequently removed, and the valve is held in position by the radial force that the valve stent exerts on the aortic annulus and aortic root. This valve is described as a sutureless rapid deployment valve (SURD).

These solutions attempt to reduce surgical trauma by reducing cross-clamp and cardiopulmonary bypass (CPB) times. Furthermore, newer prostheses have increased the utility of minimally invasive approaches through anterolateral thoracotomy and upper hemisternotomy. These approaches aim to reduce short-term morbidity associated with surgical intervention while maintaining the long-term surgical benefits. This review aims to determine whether any important differences in the outcomes for patients treated with these two new aortic valve solutions occur.

\section{Methods}

\section{Literature search strategy}

This meta-analysis was performed in accordance with the Preferred Reporting Items for Systematic Reviews and Meta-Analyses (PRISMA) recommendations and guidelines. The search strategy queried the electronic databases EMBASE, Ovid Medline, Scopus, the entire Cochrane Central Register of Controlled Trails (CCRCT), Cochrane Database of Systematic Reviews (CDSR) and the Database of Abstracts of Reviews of Effects (DARE) from inception to 03 October 2019. The search terms were "(sutureless valve OR Perceval) AND (rapid deployment valve OR Intuity OR Enable) AND (aortic valve surgery OR aortic valve replacement)". The references of previous systematic reviews were assessed to ensure no additional publications were missed.

\section{Selection criteria}

Eligibility for inclusion in this systematic review and meta-analysis included comparative studies that assessed the outcomes of adult patients undergoing aortic valve replacement with rapid deployment and sutureless valve prostheses for the treatment of aortic valve disease of any etiology. In order to ensure sufficient center experience, papers were only included if more than ten cases were reported in each arm. Only English language papers were analyzed. Studies with inadequate data regarding outcomes and studies that only included patients treated with the now removed $3 \mathrm{~F}$ Enable prosthesis in the rapid deployment arm were excluded. If centers reported outcomes of overlapping patient series, the most contemporary series was analyzed. Conference abstracts, case reports, editorials, reviews and expert opinion pieces were excluded. Article identification and inclusion were performed independently by two authors (CDF and $\mathrm{AC}$ ) and discussed until consensus was reached.

\section{Data extraction}

For the assessed papers, data was extracted from the reviewed text, tables and figures. Data was extracted independently by two authors ( $\mathrm{LH}$ and $\mathrm{BM})$, checked and validated by a senior author (CDF) and any discrepancies were reviewed and discussed until consensus was reached. The recorded parameters included: number of cases in the series, concomitant procedure undertaken, surgical 
approach, average age, average risk score, mortality, stroke, paravalvular leak, mean gradient, cross-clamp and CPB times, post-operative pacemaker implantation requirement, intensive care unit (ICU) and hospital length of stay (LOS). Complete datasets were used for primary analysis and two studies $(4,5)$ included propensity matched pairs. Propensity matched data was also extracted and assessed in separate analyses.

\section{Statistical analysis}

Meta-analysis of operative and post-operative variables was performed. Incidence data was assessed using Comprehensive Meta-analysis v3.3 (Biostat, Englewood, NJ, USA). For continuous data with central tendency described using median values, the mean and standard deviation were estimated using calculations described by Wan and colleagues (6). Comparative outcomes were assessed using Review Manager v5.3 (Cochrane Collaboration, Copenhagen, Denmark). Due to the varied patient populations, a random effects model was chosen for all analyses. Summary measures were expressed as odds ratios and differences in mean as appropriate. Data significance and heterogeneity were assessed using the Cochrane $\mathrm{Q}$ statistic and the $\mathrm{I}^{2}$ test statistic respectively, with significance set at a $\mathrm{P}$ value $<0.05$ and significant heterogeneity denoted by an $\mathrm{I}^{2}$ value $>50 \%$. Publication bias was assessed through visual inspection of generated funnel plots and Egger's regression tests with Comprehensive Meta-analysis. Sensitivity analysis was performed using a "leave-one-out" analysis. Meta-regression was performed using Comprehensive Meta-Analysis to explore sources of heterogeneity, particularly the impact of study size and enrolment date on outcomes. Primary outcomes of interest were cross-clamp time, CPB time, pacemaker implantation rate, paravalvular leak rate and transvalvular gradient. Secondary outcomes included mortality, stroke, hospital and ICU LOS.

\section{Quality analysis}

Study quality was assessed using the modified Canadian National Institute of Health Economics (CNIHE) assessment tool for case series (7) (Figure S1). Studies were considered to be of high quality if they addressed at least 15 of the 19 criteria outlined in the CNIHE tool, of moderate quality if $13-15$ criteria were addressed and of low quality if fewer than 13 criteria were addressed.

\section{Results}

The search strategy revealed 407 citations for review after duplications were removed. No additional citations were identified on review of reference lists. After full review, seven papers met the pre-determined inclusion criteria (4,5,8-12) (Figure S2). The publications included a total of 4,076 patients, where 2,426 patients received SURD (Perceval valve) and 1,650 patients received RDV (Intuity valve). In our analysis one study was deemed of high quality, five of moderate quality and one of low quality (Table 1). As the majority of studies were of moderate quality, no subgroup analysis was performed. The pooled mean age of patients receiving SURD was 77.1 years [95\% confidence interval (CI), 76.8-77.4] and the pooled mean age of patients undergoing RDV was 74.3 years (95\% CI: 73.175.6). Overall patients receiving SURD were significantly older than patients receiving RDV by 2.5 years $(95 \%$ CI: $\left.1.1-4.0 ; \mathrm{P}=0.001 ; \mathrm{I}^{2}=77 \%\right)$. The Society of Thoracic Surgeons Predicted Risk of Mortality (STS-PROM) score was reliably reported in four studies $(4,5,9,10)$. The pooled mean STS-PROM score was 3.13 (95\% CI: 2.38-3.88) for SURD and 2.60 (95\% CI: 2.46-2.76) for RDV, with no statistical difference between the two modalities $(\mathrm{P}=0.31$; $\mathrm{I}^{2}=94 \%$ ) (Table 2).

Overall, all-cause mortality was reported in 3,998 patients (2,351 SURD, 1,647 RDV) across all seven studies $(4,5,8-12)$. In the overall studied population, there were 95 deaths $(2.4 \%)$ with 54 deaths $(2.3 \%)$ in the SURD group and 41 deaths $(2.5 \%)$ in the RDV group. There was no difference in overall mortality between SURD and RDV (95\% CI: 0.64-1.57; $\mathrm{P}=1.00 ; \mathrm{I}^{2}=0$ ) (Figure S3). When assessing propensity matched data, there was no difference in overall mortality between SURD and RDV $(\mathrm{P}=0.90$; $\left.\mathrm{I}^{2}=0 \%\right)$.

Stroke rates were reported in 3,670 patients $(2,122$ SURD, 1,548 RDV) across six studies (4,5,8-10,12). There were 88 strokes $(2.5 \%)$ in the patient population with 48 $(2.3 \%)$ occurring in SURD patients and 40 (2.6\%) in the RDV population. There was no difference in stroke rate between SURD and RDV ( $\left.\mathrm{P}=0.89 ; \mathrm{I}^{2}=33 \%\right)$ (Figure S4). When assessing propensity matched data there was no difference in stroke rate between SURD and RDV $(\mathrm{P}=0.7$; $\left.\mathrm{I}^{2}=0 \%\right)$.

The presence of moderate or worse paravalvular regurgitation was reported in 3,400 patients (1,982 SURD, 1,418 RDV) across all seven studies. Overall, 36 patients $(1.0 \%)$ had moderate or worse paravalvular regurgitation 

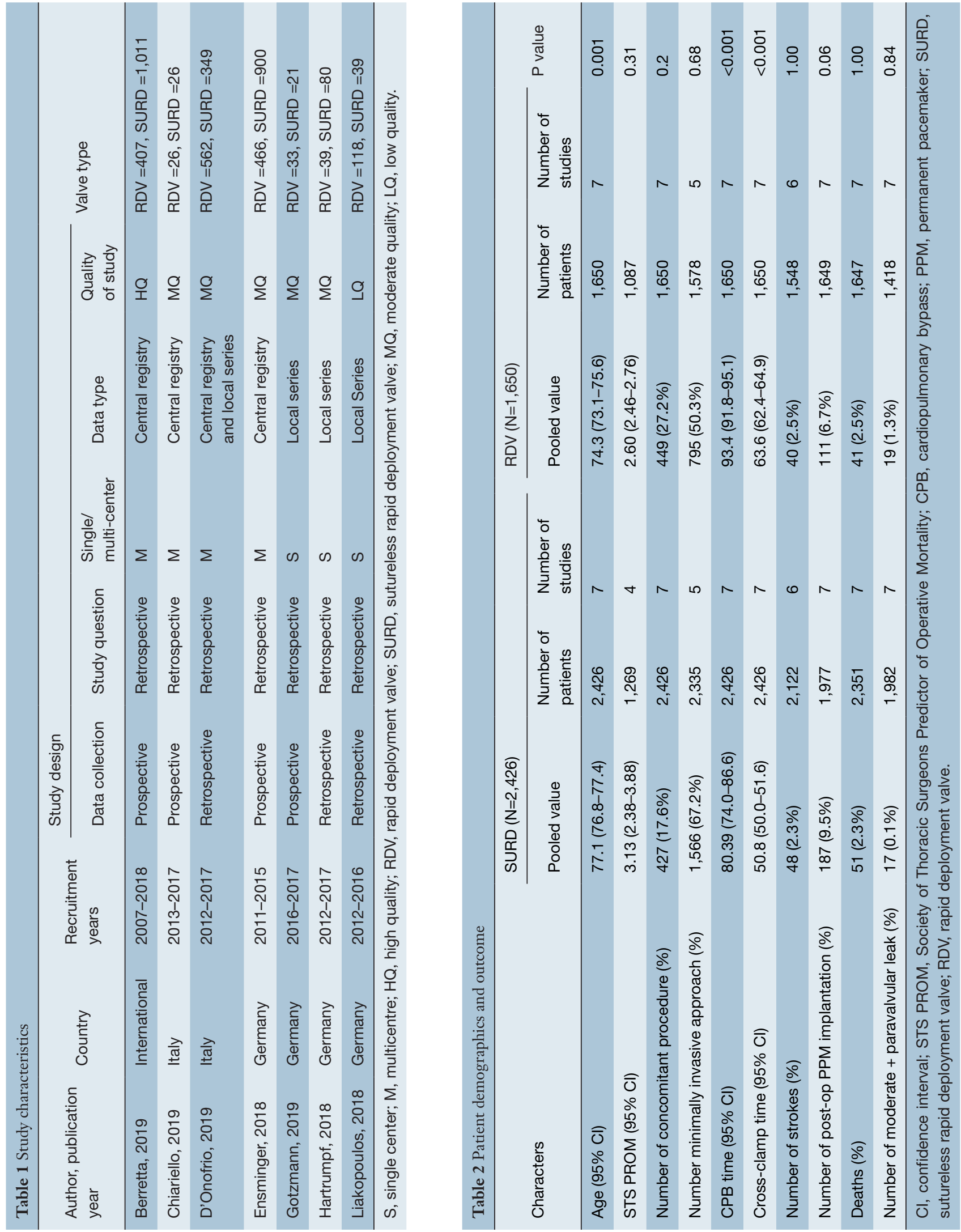


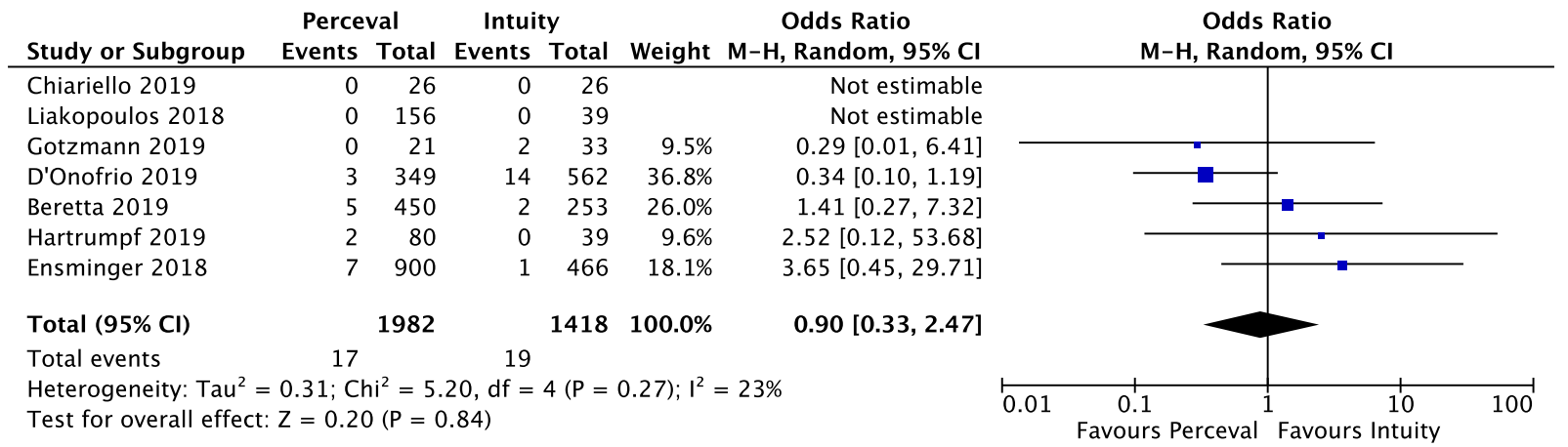

Figure 1 Forest plot of the incidence moderate or worse post-operative paravalvular regurgitation.

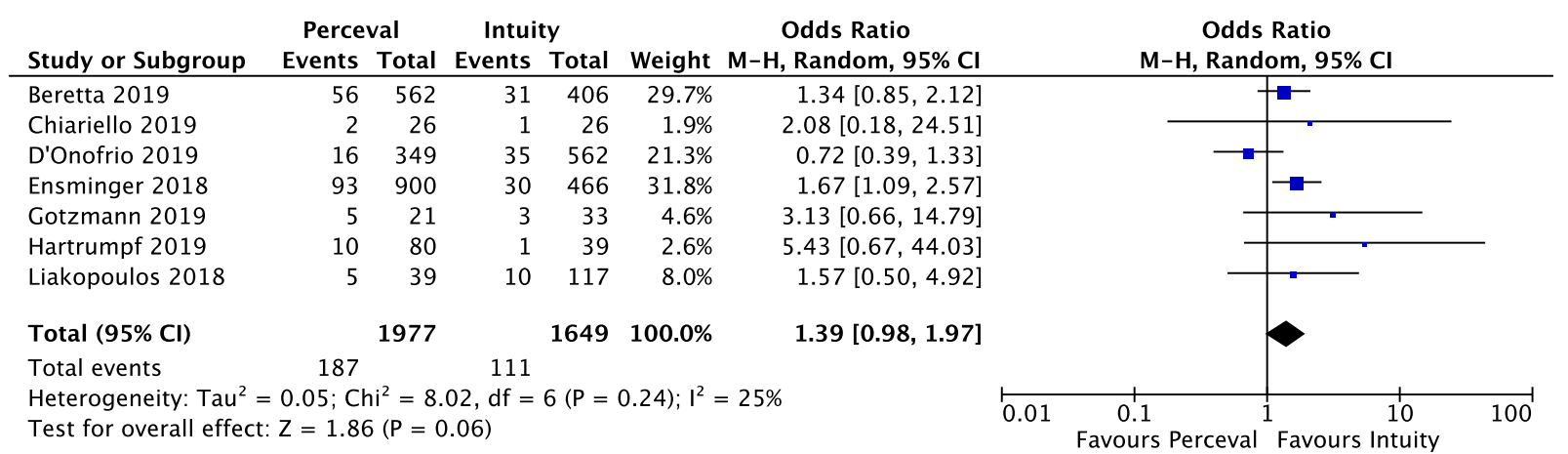

Figure 2 Forest plot of the rates of post-operative pacemaker implantation.

post-operatively and of these, 17 patients $(0.1 \%)$ received SURD and 19 patients $(1.3 \%)$ received RDV. There was no significant difference in the rate of moderate or worse postoperative paravalvular leak between the two prosthesis types $\left(\mathrm{P}=0.84 ; \mathrm{I}^{2}=23 \%\right)$ (Figure 1). When assessing propensity matched data, there was no significant difference in the rate of moderate or worse post-operative paravalvular leak between the two prosthesis types $\left(\mathrm{P}=0.4 ; \mathrm{I}^{2}=0 \%\right)$ (Figure S5). Five studies reported the presence of mild post-operative paravalvular regurgitation $(5,8-10,12)$ in a total of 2,331 patients (1,436 SURD, 895 RDV). Overall, mild post-operative regurgitation was identified in 156 patients $(6.7 \%)$, including $126(8.8 \%)$ patients treated with SURD and 30 (3.4\%) patients treated with RDV. There was a significant increase in the risk of mild paravalvular regurgitation post-operatively associated with SURD (OR, 2.51; 95\% CI: 1.35-4.68; $\mathrm{P}=0.004 ; \mathrm{I}^{2}=39 \%$ ) (Figure S6). When assessing data from propensity matched studies, there was still a significantly increased risk of mild paravalvular regurgitation associated with SURD (OR, 2.71; 95\% CI: 1.11-6.58; $\mathrm{P}=0.03 ; \mathrm{I}^{2}=43 \%$ ) (Figure $S 7$ ).
Post-operative pacemaker implantation was reported in 3,626 patients (1,977 SURD, 1,649 RDV) across all seven studies. Overall, 298 patients $(8.2 \%)$ required postoperative pacemaker implantation, of these 187 patients (9.5\%) received SURD and 111 patients $(6.7 \%)$ received RDV. There was a trend towards an increased risk of pacemaker implantation associated with SURD, although this did not reach statistical significance (OR, 1.36; 95\% CI: 0.98-1.97; $\mathrm{P}=0.06 ; \mathrm{I}^{2}=25 \%$ ) (Figure 2). When including only propensity matched data, the increased risk of pacemaker implantation associated with SURD reached significance (OR, 1.48; 95\% CI: 1.05-2.09; $\mathrm{P}=0.02 ; \mathrm{I}^{2}=0 \%$ ) (Figure S8).

Mean post-operative transvalvular gradient was reported in 4,076 patients (2,426 SURD, 1,650 RDV) across all seven studies. The transvalvular pooled mean gradient was $13.9 \mathrm{mmHg}$ (95\% CI: 12.4-14.3) across SURD and $10.8 \mathrm{mmHg}$ (95\% CI: 10.2-11.4) across RDV. There was a significantly increased gradient across SURD compared to RDV of $2.5 \mathrm{mmHg}$ (95\% CI: $\left.1.2-3.8 ; \mathrm{P}<0.001 ; \mathrm{I}^{2}=90 \%\right)$ (Figure 3). When assessing available propensity matched data, there was still a significantly increased gradient across 


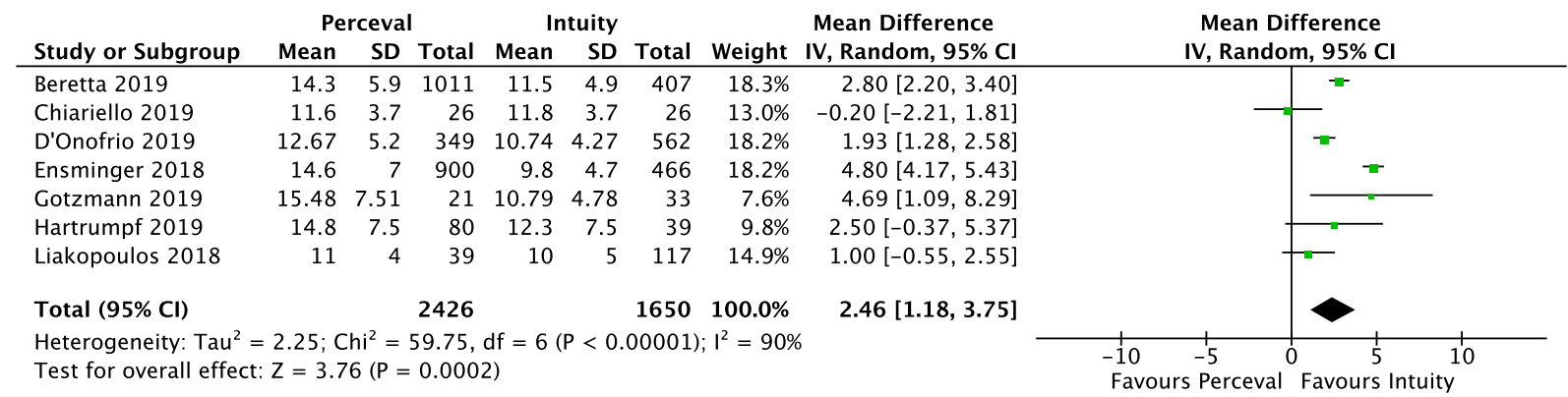

Figure 3 Forest plot comparing pooled mean post-operative transvalvular gradients $(\mathrm{mmHg})$.

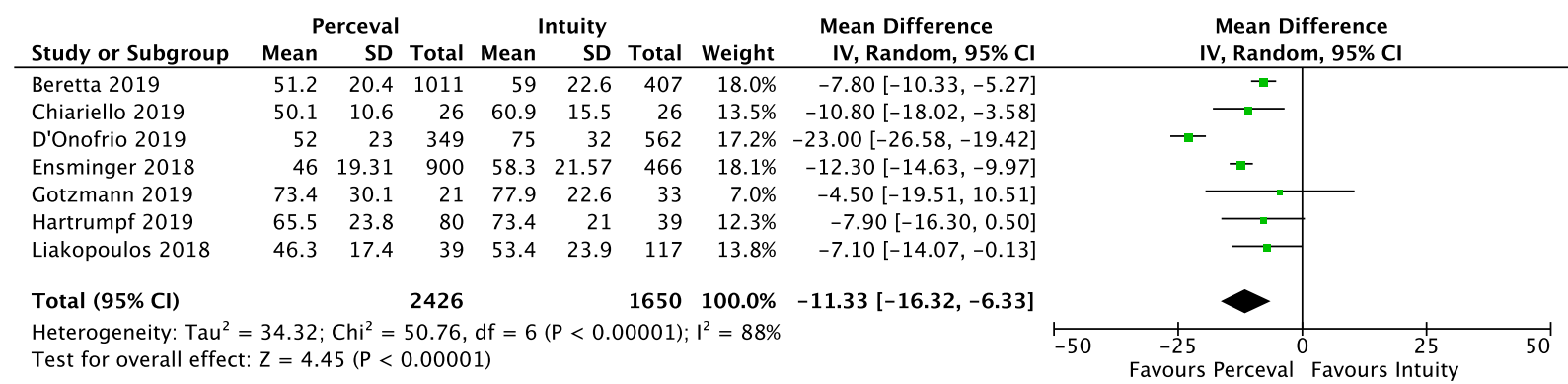

Figure 4 Forest plot comparing pooled mean cross-clamp times (minutes).

SURD compared to RDV of $2.3 \mathrm{mmHg}$ (95\% CI: 1.1-3.5; $\mathrm{P}<0.001 ; \mathrm{I}^{2}=77 \%$ ) (Figure S9). No single study was identified as a source of the high degree of heterogeneity on sensitivity analysis. There was no evidence of publication bias on visual inspection via funnel plots or on Egger's regression modelling $(\mathrm{P}=0.65)$. There was insufficient reported data to determine the proportion of patients with post-operative patient-prosthesis mismatch (PPM) or excessively high postoperative gradients with each valve type.

Cross-clamp time was reported in 4,076 patients $(2,426$ SURD, 1,650 RDV) across all seven studies. The pooled mean cross-clamp time for SURD was 50.8 minutes $(95 \%$ CI: 50.0-51.6) and the pooled mean cross-clamp time for RDV was 63.6 minutes (95\% CI: 62.4-64.9). SURD valves had a significantly shorter mean cross-clamp time of 11.3 minutes (95\% CI: $6.3-16.3 ; \mathrm{P}<0.001 ; \mathrm{I}^{2}=88 \%$ ) when compared to RDV (Figure 4). When interrogating data from propensity matching where available, there was still a significant reduction in mean cross-clamp times of 9.4 minutes (95\% CI: 5.27-13.5; $\mathrm{P}<0.001 ; \mathrm{I}^{2}=64 \%$ ) with SURD valves compared to RDV (Figure S10). Meta-regression demonstrated that neither study size nor median year of enrolment were significant contributors to the variance of mean cross-clamp times. Sensitivity analysis did not reveal any significant reason for heterogeneity. There was no evidence of publication bias on visual inspection of funnel plot or on Egger's regression modelling $(\mathrm{P}=0.48)$.

Five studies $(4,8,9,11,12)$ reported outcomes for 2,182 isolated AVR patients (1,296 SURD, $866 \mathrm{RDV})$. The pooled mean cross-clamp time was 46.4 minutes (95\% CI: 40.652.2) for patients undergoing isolated AVR with SURD and 58.1 minutes (95\% CI: 47.4-68.7) for patients undergoing isolated AVR with RDV. There was a significantly shorter cross-clamp time with the use of SURD by 11.7 minutes (95\% CI: 2.8-20.6; $\mathrm{P}=0.01 ; \mathrm{I}^{2}=95 \%$ ) (Figure S11). There was no evidence of publication bias (Egger's regression $\mathrm{P}=0.74$ ).

CPB times were reported in 4,076 patients (SURD $=2,426, \mathrm{RDV}=1,650)$ across all studies. The pooled mean CPB time was 80.4 minutes (95\% CI: 74.0-86.8) for SURD patients and 93.4 minutes (95\% CI: 91.8-95.1) for RDV patients. There was a significantly shorter $\mathrm{CPB}$ time for patients treated with SURD compared with RDV by 16.2 minutes (95\% CI: 9.5-22.9; $\mathrm{P}<0.001 ; \mathrm{I}^{2}=87 \%$ ) (Figure 5). When assessing data from propensity matched studies where available, there was a significantly shorter CPB time for patients treated with SURD compared with RDV by 12.5 minutes (95\% CI: 7.6-17.4; $\mathrm{P}<0.001 ; \mathrm{I}^{2}=52 \%$ ) 


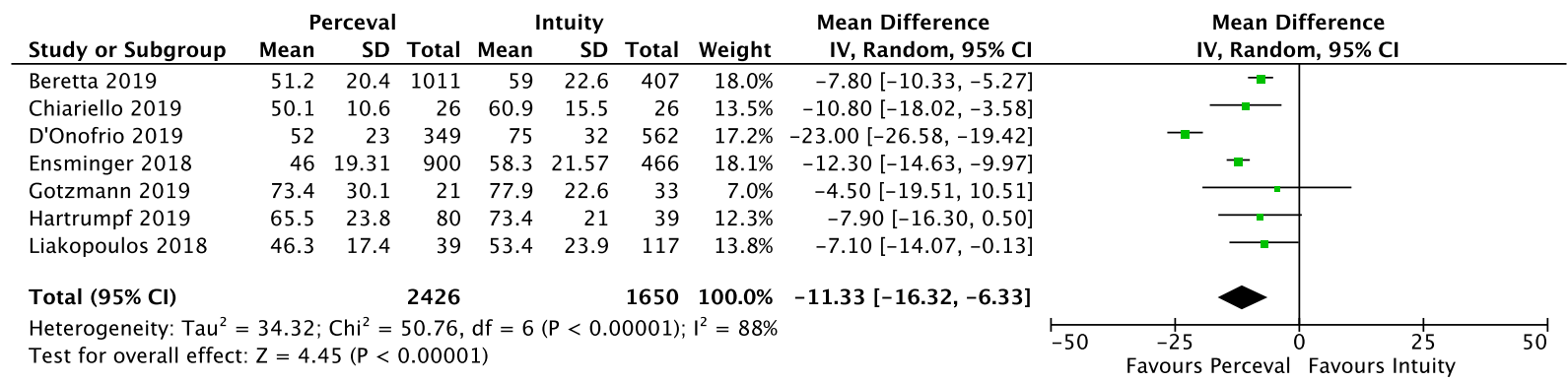

Figure 5 Forest plot comparing pooled mean cardiopulmonary bypass times (minutes).

(Figure S12). There was no evidence of publication bias (Egger's regression $\mathrm{P}=0.76$ ). The pooled mean $\mathrm{CPB}$ time for isolated AVR with SURD was 71.0 minutes (95\% CI: 60.4-81.6). The pooled mean CPB time for isolated AVR with RDV was 87.0 minutes (95\% CI: 85.0-88.9). There was a significantly shorter duration for $\mathrm{CPB}$ of 15.7 minutes (95\% CI: 4.2-27.1; $\mathrm{P}=0.007 ; \mathrm{I}^{2}=94 \%$ ) for patients receiving SURD (Figure S13). There was no evidence of publication bias. Sensitivity analysis revealed that a significant amount of variance of CPB time was due to the study by D'Onofrio and colleagues (4) and it is unclear why this study population produced such different results from the remainder of the study populations. If this study is excluded, CPB times remain shorter for patients receiving SURD by 8.8 minutes (95\% CI: $6.0-11.7 ; \mathrm{P}<0.001 ; \mathrm{I}^{2}=23 \%$ ).

ICU LOS was reported in 3,165 patients (2,077 SURD, $1,088 \mathrm{RDV})$ across six studies (5,8-12). There was a trend towards a shorter ICU LOS with SURD, although this did not reach statistical significance (95\% CI: 2.26-0.01; $\mathrm{P}=0.05 ; \mathrm{I}^{2}=84 \%$ ) (Figure S14). Significant heterogeneity was introduced in the study by Liakopoulos et al. (12). The mean ICU and hospital LOS was calculated from the reported median and interquartile range and it is likely that the mean LOS is skewed by several disproportionally long ICU LOS. Exclusion of this study confirms no significant difference in ICU LOS $\left(\mathrm{P}=0.1 ; \mathrm{I}^{2}=23 \%\right)$.

Hospital LOS was reported in 3,165 patients $(2,077$ SURD, 1,088 RDV) across six studies (5,8-12). There was no significant difference in the in the hospital LOS for patients receiving the two valve types $\left(\mathrm{P}=0.33 ; \mathrm{I}^{2}=96 \%\right)$ (Figure S15).

The primary outcomes are summarised in Table 3.

\section{Discussion}

This meta-analysis assessed the procedural and early clinical outcomes of patients undergoing aortic valve replacement with either SURD or RDV. A major perceived benefit of RDV and SURD over conventional aortic valve replacement is the speed of valve siting, which reduces cross-clamp and CPB times and may be of particular relevance for patients requiring concomitant procedures. It has been demonstrated that longer CPB and cross-clamp times are associated with increased mortality and early morbidity (13-15). In terms of reducing procedure time, there was a clinically significant reduction in cross-clamp and $\mathrm{CPB}$ times associated with the use of SURD. There was significant heterogeneity in the analysis of both CPB $\left(\mathrm{I}^{2}=94 \%\right)$ and cross-clamp times $\left(\mathrm{I}^{2}=88 \%\right)$. Leave-one-out sensitivity analysis determined that the study by D'Onofrio et al. contributed a significant amount of heterogeneity into the difference for CPB times. However, it is unclear why the population in this group was different from the rest of the study population. Post-hoc subgroup analysis of patients undergoing isolated aortic valve replacement was undertaken to limit the heterogeneity introduced by patients undergoing a wide variety of concomitant procedures. The CPB and cross-clamp times for SURD remained significantly shorter than RDV, although there remained significant heterogeneity between groups. There was no obvious source for the heterogeneity. The difference in cross-clamp and CPB times demonstrated in this study did not result in a difference in mortality. When including the propensity matched data from two studies $(4,5)$ into pooled analysis, there was a reduction in the degree of observed heterogeneity for CPB and cross-clamp times, with a significant reduction in procedural times in favor of SURD. This suggests that the observed heterogeneity is likely due to differences in patient population backgrounds between the two groups.

Despite the increase in TAVR in recent years, surgical aortic valve replacement will continue to have an ongoing 


\begin{tabular}{|c|c|c|c|c|c|}
\hline \multirow[b]{2}{*}{ Outcomes } & \multirow{2}{*}{$\begin{array}{l}\text { No. of participants } \\
\text { (studies), follow up }\end{array}$} & \multirow{2}{*}{$\begin{array}{l}\text { Certainty of the } \\
\text { evidence (GRADE) }\end{array}$} & \multirow{2}{*}{$\begin{array}{l}\text { Relative effect } \\
(95 \% \mathrm{Cl})\end{array}$} & \multicolumn{2}{|l|}{ Anticipated absolute effects } \\
\hline & & & & Risk with RDV & $\begin{array}{l}\text { Risk difference with } \\
\text { outcomes for SURD }\end{array}$ \\
\hline Overall mortality & $\begin{array}{l}2,836 \text { (7 observational } \\
\text { studies) }\end{array}$ & $\oplus \oplus \bigcirc \bigcirc$ low & $\begin{array}{l}\text { OR } 0.91 \\
\text { (0.51 to } 1.63)\end{array}$ & 23 per 1,000 & $\begin{array}{l}2 \text { fewer per } 1,000 \\
\text { (11 fewer to } 14 \text { more) }\end{array}$ \\
\hline Stroke & $\begin{array}{l}3,670 \text { (6 observational } \\
\text { studies) }\end{array}$ & $\oplus \oplus \bigcirc \bigcirc$ low & $\begin{array}{l}\text { OR } 1.04 \\
\text { (0.55 to } 1.98)\end{array}$ & 26 per 1,000 & $\begin{array}{l}1 \text { more per } 1,000 \\
\text { (11 fewer to } 24 \text { more) }\end{array}$ \\
\hline $\begin{array}{l}\text { Paravalvular leak: } \\
\text { mild }\end{array}$ & $\begin{array}{l}2,331 \text { ( } 5 \text { observational } \\
\text { studies) }\end{array}$ & $\oplus \bigcirc \bigcirc \bigcirc$ very low $^{a}$ & $\begin{array}{l}\text { OR } 2.51 \\
\text { (1.35 to } 4.68)\end{array}$ & 34 per 1,000 & $\begin{array}{l}47 \text { more per } 1,000 \\
\text { (11 more to } 106 \text { more) }\end{array}$ \\
\hline $\begin{array}{l}\text { Paravalvular leak: } \\
\text { moderate }+\end{array}$ & $\begin{array}{l}3,400 \text { ( } 7 \text { observational } \\
\text { studies) }\end{array}$ & $\oplus \bigcirc \bigcirc \bigcirc$ very low $^{a}$ & $\begin{array}{l}\text { OR } 0.90 \\
(0.33 \text { to } 2.47)\end{array}$ & 13 per 1,000 & $\begin{array}{l}1 \text { fewer per } 1,000 \\
\text { (9 fewer to } 19 \text { more) }\end{array}$ \\
\hline $\begin{array}{l}\text { Pacemaker } \\
\text { implantation }\end{array}$ & $\begin{array}{l}3,626 \text { ( } 7 \text { observational } \\
\text { studies) }\end{array}$ & $\oplus \bigcirc \bigcirc \bigcirc$ very low $^{b}$ & $\begin{array}{l}\text { OR } 1.39 \\
(0.98 \text { to } 1.97)\end{array}$ & 67 per 1,000 & $\begin{array}{l}24 \text { more per } 1,000 \\
\text { ( } 1 \text { fewer to } 57 \text { more) }\end{array}$ \\
\hline $\begin{array}{l}\text { Mean post-op } \\
\text { gradient }\end{array}$ & $\begin{array}{l}4,076 \text { (7 observational } \\
\text { studies) }\end{array}$ & $\oplus \oplus \bigcirc \bigcirc$ low & - & $\begin{array}{l}\text { The mean mean post-op } \\
\text { gradient was } 10.8 \mathrm{mmHg}\end{array}$ & $\begin{array}{l}\text { MD } 2.46 \mathrm{mmHg} \text { higher } \\
\text { (1.18 higher to } 3.75 \text { higher) }\end{array}$ \\
\hline $\begin{array}{l}\text { Cross-clamp } \\
\text { time }\end{array}$ & $\begin{array}{l}4,076 \text { ( } 7 \text { observational } \\
\text { studies) }\end{array}$ & $\oplus \oplus \bigcirc \bigcirc$ low $^{c}$ & - & $\begin{array}{l}\text { The mean cross-clamp } \\
\text { time was } 63.6 \text { minutes }\end{array}$ & $\begin{array}{l}\text { MD } 11.33 \text { minutes lower } \\
\text { (16.32 lower to } 6.33 \text { lower) }\end{array}$ \\
\hline CPB time & $\begin{array}{l}4,076 \text { (7 observational } \\
\text { studies) }\end{array}$ & $\oplus \oplus \bigcirc \bigcirc$ low $^{c}$ & - & $\begin{array}{l}\text { The mean CPB time was } \\
93.4 \text { minutes }\end{array}$ & $\begin{array}{l}\text { MD } 16.18 \text { minutes lower } \\
\text { (22.88 lower to } 9.48 \text { lower) }\end{array}$ \\
\hline
\end{tabular}

The risk in the intervention group (and its $95 \% \mathrm{Cl}$ ) is based on the assumed risk in the comparison group and the relative effect of the intervention (and its 95\% Cl). GRADE Working Group grades of evidence-high certainty: we are very confident that the true effect lies close to that of the estimate of the effect; moderate certainty: we are moderately confident in the effect estimate: the true effect is likely to be close to the estimate of the effect, but there is a possibility that it is substantially different; low certainty: our confidence in the effect estimate is limited: the true effect may be substantially different from the estimate of the effect; very low certainty: we have very little confidence in the effect estimate: the true effect is likely to be substantially different from the estimate of effect. a , surgical experience with these new prostheses is known to affect decisions in sizing. This has a direct impact on post-operative trans-valvular mean gradients. There is limited data available to assess learning curve effects and surgical experience; ${ }^{b}$, known significant learning curve that has a direct impact on pacemaker implantation rates. Limited data present on individual surgeon experience; ${ }^{\circ}$, learning curve may affect operative duration times. Limited data on operator experience. SURD, sutureless rapid deployment valve; RDV, rapid deployment valve; $\mathrm{Cl}$, confidence interval; OR, odds ratio; $\mathrm{MD}$, mean difference; $\mathrm{CPB}$, cardiopulmonary bypass.

role, particularly in low-risk patients and those requiring complicated procedures. As part of a drive to improve shortterm outcomes associated with surgical procedures, there has been an increasing number of patients undergoing aortic valve replacement via minimally invasive approaches; the most common access incisions are a partial upper hemisternotomy and a right anterior thoracotomy. These approaches have demonstrated benefits of reduced incidence of post-operative atrial fibrillation, shorter hospital and ICU LOS and a reduced blood transfusion requirement compared with conventional full sternotomy, with no significant difference in mortality or perioperative stroke (16-18). Despite these benefits, minimally invasive approaches have longer cross-clamp and CPB times and are technically more demanding. The development of durable rapid deployment and sutureless aortic valves that simplify aortic valve replacement may make minimally invasive approaches more appealing to a wider group of surgeons and potentially improve the short-term outcomes of surgery without putting patients at risk of prolonged CPB and cross-clamp times, particularly during the learning curve phase.

The rate of paravalvular regurgitation is an important area of comment. We demonstrated that $1.0 \%$ of all patients studied developed moderate or worse paravalvular regurgitation with no significant difference between the two valve designs. Mild paravalvular regurgitation was demonstrated in $6.7 \%$ of all studied patients, and was significantly increased with SURD compared to RDV. 
Paravalvular regurgitation is a fairly common occurrence even after conventional aortic valve replacement, occurring in $2-6 \%$ of patients $(19,20)$. Experience with conventional valve replacement suggest that mild paravalvular regurgitation may be associated with hemolysis but has no detrimental effect on cardiac performance or mortality outcomes $(19,21)$. However, more contemporary experience in the context of transcatheter valve implantation raises concerns that even mild paravalvular regurgitation may be detrimental to patient survival (22).

We demonstrated that the mean gradient across SURD was $2.46 \mathrm{mmHg}$ higher than the mean gradient across RDV. Excellent transvalvular gradients across RDV have previously been recognized and is proposedly attributed to the subannular balloon expanded skirt, which enlarges the left ventricular outflow tract, promoting increased laminar blood flow through the valve annulus $(23,24)$. Whether this $2.5 \mathrm{mmHg}$ represents a clinically significant difference is uncertain. Unfortunately, we were unable to compare rates of PPM due to differences in data reporting between studies. Sizing SURD has been an important area of interest in recent times as correct sizing is critical. Oversizing SURD has been an issue due to an understandable concern of surgeons looking to avoid para-valvular regurgitation. However, oversizing leads to incomplete expansion of the stent frame, preventing complete leaflet opening, thus reducing the effective orifice area leading to increased gradients. A grossly oversized valve will also result in stent frame infolding (25). The issue with sizing led to an industry sponsored alert in 2011 to increase surgeon awareness of the possible implications of oversizing the Perceval S valve (26). The importance of PPM is perhaps a slightly controversial topic. Some authors suggested an increased mid-term mortality and worsened longterm cardiological outcomes (such as left ventricular mass regression and presentations with heart failure) (27-29) with PPM, while others demonstrated no clinical difference in terms of outcome following aortic valve replacement $(30,31)$. Despite this uncertainty, it is reasonable to aim to achieve the lowest possible post-operative transvalvular gradient.

There was no significant difference in permanent pacemaker implantation (PPI) rates between the two valve types. However, the overall PPI rates of $8.22 \%$ were high compared to the expected rates following surgical aortic valve replacement, which is $1.9-2.7 \%(32-35)$. Pacemaker implantation rate is an important performance indicator. Patients who require PPI after aortic valve replacement have reduced risk-adjusted long-term survival compared those who do not require pacemaker implantation $(35,36)$. Implantation technique has been shown to be an important factor that can impact pacemaker implantation rates, particularly with regards to the Perceval valve. Meticulous attention to annular debridement, valve sizing and implantation depth with regards to the LVOT reduces post-operative PPI requirement (37). There is also a clear learning curve with implanting the new devices, with PPI rates declining as experience with devices grows $(8,37)$. Reducing the morbidity through ensuring meticulous surgical technique will be essential to maintain excellent surgical outcomes in an increasingly low-risk surgical population, as the majority of high-risk patients receive TAVR.

\section{Limitations}

There are several limitations identified in this study. There was significant heterogeneity in several important parameters and the cause of this heterogeneity was often not identified and controlled for. It is likely that heterogeneity arose from the different patient populations and center experiences, as the degree of heterogeneity reduced when only propensity matched data was included from the studies by D'Onofrio et al. and Ensminger et al. The use of different risk scores made it impossible to compare and adjust for the pre-operative risk of patients between studies. Furthermore, there was insufficient data to determine the effect that the learning curve has on outcomes. The learning curve is a particularly important consideration for outcomes such as paravalvular regurgitation, post-operative transvalvular gradient and pacemaker implantation rates. Overall, the quality of data was deemed to be moderate and all studies were retrospective analyses, although several studies used prospectively collected databases. All included studies were comparative, although none were randomized. There is also limited long-term data given the recent development of the two valves and in time, analysis of longterm data will be necessary for assessing ongoing outcomes with this technology.

\section{Conclusions}

This meta-analysis comparing SURD and RDV demonstrated no difference in mortality or stroke rates. There was a significant reduction in cross-clamp and CPB times associated with SURD. This may be of benefit for patients requiring multiple concomitant procedures and increase the utility of minimally invasive valve replacement. 
However, SURD was associated with higher postoperative transvalvular gradients and a higher incidence of paravalvular regurgitation.

\section{Acknowledgments}

None.

\section{Footnote}

Conflicts of Interest: The authors have no conflicts of interest to declare.

Open Access Statement: This is an Open Access article distributed in accordance with the Creative Commons Attribution-NonCommercial-NoDerivs 4.0 International License (CC BY-NC-ND 4.0), which permits the noncommercial replication and distribution of the article with the strict proviso that no changes or edits are made and the original work is properly cited (including links to both the formal publication through the relevant DOI and the license). See: https://creativecommons.org/licenses/by-nc-nd/4.0/.

\section{References}

1. Iung B, Baron G, Butchart EG, et al. A prospective survey of patients with valvular heart disease in Europe: The Euro Heart Survey on Valvular Heart Disease. Eur Heart J 2003;24:1231-43.

2. Iung B, Vahanian A. Epidemiology of valvular heart disease in the adult. Nat Rev Cardiol 2011;8:162-72.

3. Sedrakyan A, Dhruva SS, Sun T, et al. Trends in Use of Transcatheter Aortic Valve Replacement by Age. JAMA 2018;320:598-600.

4. D'Onofrio A, Salizzoni S, Filippini C, et al. Surgical aortic valve replacement with new-generation bioprostheses: Sutureless versus rapid-deployment. J Thorac Cardiovasc Surg 2019. [Epub ahead of print].

5. Ensminger S, Fujita B, Bauer T, et al. Rapid Deployment Versus Conventional Bioprosthetic Valve Replacement for Aortic Stenosis. J Am Coll Cardiol 2018;71:1417-28.

6. Wan X, Wang W, Liu J, et al. Estimating the sample mean and standard deviation from the sample size, median, range and/or interquartile range. BMC Med Res Methodol 2014; $14: 135$.

7. IoHE. Quality Appraisal of Case Series Studies Checklist. Edmonton (AB): Institute of Health Economics; 2014. Edmonton (AB) 2014.
8. Berretta P, Andreas M, Carrel TP, et al. Minimally invasive aortic valve replacement with sutureless and rapid deployment valves: a report from an international registry (Sutureless and Rapid Deployment International Registry) dagger. Eur J Cardiothorac Surg 2019;56:793-9.

9. Chiariello GA, Bruno P, Villa E, et al. Aortic Valve Replacement in Elderly Patients With Small Aortic Annulus: Results With Three Different Bioprostheses. Innovations (Phila) 2019;14:27-36.

10. Gotzmann $M$, Wilbring $M$, Charitos E, et al. Hemodynamic Comparison of Sutureless and RapidDeployment Valves with Conventional Bioprostheses. Thorac Cardiovasc Surg 2019. [Epub ahead of print].

11. Hartrumpf M, Kuehnel RU, Schroeter F, et al. Clinical Short-Term Outcome and Hemodynamic Comparison of Six Contemporary Bovine Aortic Valve Prostheses. Thorac Cardiovasc Surg 2019. [Epub ahead of print].

12. Liakopoulos OJ, Gerfer S, Weider S, et al. Direct Comparison of the Edwards Intuity Elite and Sorin Perceval S Rapid Deployment Aortic Valves. Ann Thorac Surg 2018;105:108-14.

13. Wesselink RM, de Boer A, Morshuis WJ, et al. Cardiopulmonary-bypass time has important independent influence on mortality and morbidity. Eur J Cardiothorac Surg 1997;11:1141-5.

14. Chalmers J, Pullan M, Mediratta N, et al. A need for speed? Bypass time and outcomes after isolated aortic valve replacement surgery. Interact Cardiovasc Thorac Surg 2014;19:21-6.

15. Salis S, Mazzanti VV, Merli G, et al. Cardiopulmonary bypass duration is an independent predictor of morbidity and mortality after cardiac surgery. J Cardiothorac Vasc Anesth 2008;22:814-22.

16. Chang C, Raza S, Altarabsheh SE, et al. Minimally Invasive Approaches to Surgical Aortic Valve Replacement: A Meta-Analysis. Ann Thorac Surg 2018;106:1881-9.

17. Paparella D, Malvindi PG, Santarpino G, et al. Full sternotomy and minimal access approaches for surgical aortic valve replacement: a multicentre propensitymatched study. Eur J Cardiothorac Surg 2020;57:709-16.

18. Welp HA, Herlemann I, Martens S, et al. Outcomes of aortic valve replacement via partial upper sternotomy versus conventional aortic valve replacement in obese patients. Interact Cardiovasc Thorac Surg 2018;27:481-6.

19. Ionescu A, Fraser AG, Butchart EG. Prevalence and clinical significance of incidental paraprosthetic valvar regurgitation: a prospective study using transoesophageal echocardiography. Heart 2003;89:1316-21. 
20. Hammermeister K, Sethi GK, Henderson WG, et al. Outcomes 15 years after valve replacement with a mechanical versus a bioprosthetic valve: final report of the Veterans Affairs randomized trial. J Am Coll Cardiol 2000;36:1152-8.

21. Rallidis LS, Moyssakis IE, Ikonomidis I, et al. Natural history of early aortic paraprosthetic regurgitation: a fiveyear follow-up. Am Heart J 1999;138:351-7.

22. Ando T, Briasoulis A, Telila T, et al. Does mild paravalvular regurgitation post transcatheter aortic valve implantation affect survival? A meta-analysis. Catheter Cardiovasc Interv 2018;91:135-47.

23. Sadri V, Bloodworth CHt, Madukauwa-David ID, et al. A mechanistic investigation of the EDWARDS INTUITY Elite valve's hemodynamic performance. Gen Thorac Cardiovasc Surg 2020;68:9-17.

24. Haverich A, Wahlers TC, Borger MA, et al. Threeyear hemodynamic performance, left ventricular mass regression, and prosthetic-patient mismatch after rapid deployment aortic valve replacement in 287 patients. J Thorac Cardiovasc Surg 2014;148:2854-60.

25. Cerillo AG, Amoretti F, Mariani M, et al. Increased Gradients After Aortic Valve Replacement With the Perceval Valve: The Role of Oversizing. Ann Thorac Surg 2018;106:121-8.

26. Group S. Perceval sutureless aortic heart valve instruction for use. In: HVV_LS-850-0002 Rev X03. 2015.

27. Hong S, Yi G, Youn YN, et al. Effect of the prosthesispatient mismatch on long-term clinical outcomes after isolated aortic valve replacement for aortic stenosis: a prospective observational study. J Thorac Cardiovasc Surg 2013;146:1098-104.

28. Mannacio V, Mannacio L, Mango E, et al. Severe prosthesis-patient mismatch after aortic valve replacement for aortic stenosis: Analysis of risk factors for early and long-term mortality. J Cardiol 2017;69:333-9.

29. Head SJ, Mokhles MM, Osnabrugge RL, et al. The

Cite this article as: Flynn CD, Williams ML, Chakos A, Hirst L, Muston B, Tian DH. Sutureless valve and rapid deployment valves: a systematic review and meta-analysis of comparative studies. Ann Cardiothorac Surg 2020;9(5):364-374. doi: 10.21037/acs-2020-surd-27 impact of prosthesis-patient mismatch on long-term survival after aortic valve replacement: a systematic review and meta-analysis of 34 observational studies comprising 27186 patients with 133141 patient-years. Eur Heart J 2012;33:1518-29.

30. Das De S, Nanjappa A, Morcos K, et al. The effect of patient-prosthesis mismatch on survival after aortic and mitral valve replacement: a 10 year, single institution experience. J Cardiothorac Surg 2019;14:214.

31. Koene BM, Soliman Hamad MA, Bouma W, et al. Impact of prosthesis-patient mismatch on early and late mortality after aortic valve replacement. J Cardiothorac Surg 2013;8:96.

32. Ram E, Amunts S, Zuroff E, et al. Outcomes of isolated surgical aortic valve replacement in the era of transcatheter aortic valve implantation. J Card Surg 2020;35:1452-7.

33. Iturra SA, Suri RM, Greason KL, et al. Outcomes of surgical aortic valve replacement in moderate risk patients: implications for determination of equipoise in the transcatheter era. J Thorac Cardiovasc Surg 2014;147:127-32.

34. Van Mieghem NM, Head SJ, de Jong W, et al. Persistent annual permanent pacemaker implantation rate after surgical aortic valve replacement in patients with severe aortic stenosis. Ann Thorac Surg 2012;94:1143-9.

35. Mehaffey JH, Haywood NS, Hawkins RB, et al. Need for Permanent Pacemaker After Surgical Aortic Valve Replacement Reduces Long-Term Survival. Ann Thorac Surg 2018;106:460-5.

36. Greason KL, Lahr BD, Stulak JM, et al. Long-Term Mortality Effect of Early Pacemaker Implantation After Surgical Aortic Valve Replacement. Ann Thorac Surg 2017;104:1259-64.

37. González Barbeito M, Estévez-Cid F, Pardo Martínez $\mathrm{P}$, et al. Surgical technique modifies the postoperative atrioventricular block rate in sutureless prostheses. J Thorac Dis 2019;11:2945-54. 


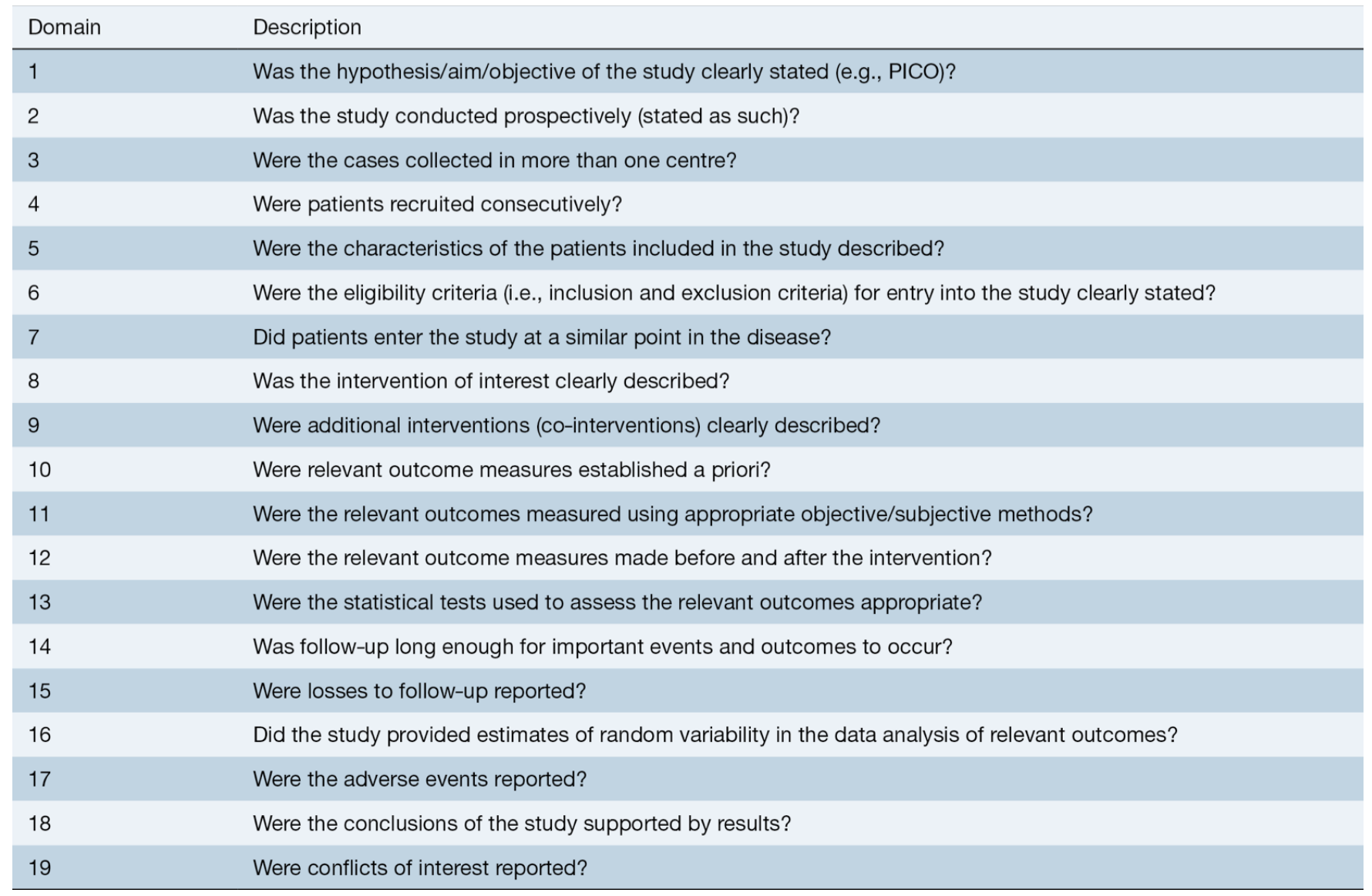

Figure S1 Modified Canadian Institute of Health Economics quality appraisal checklist.

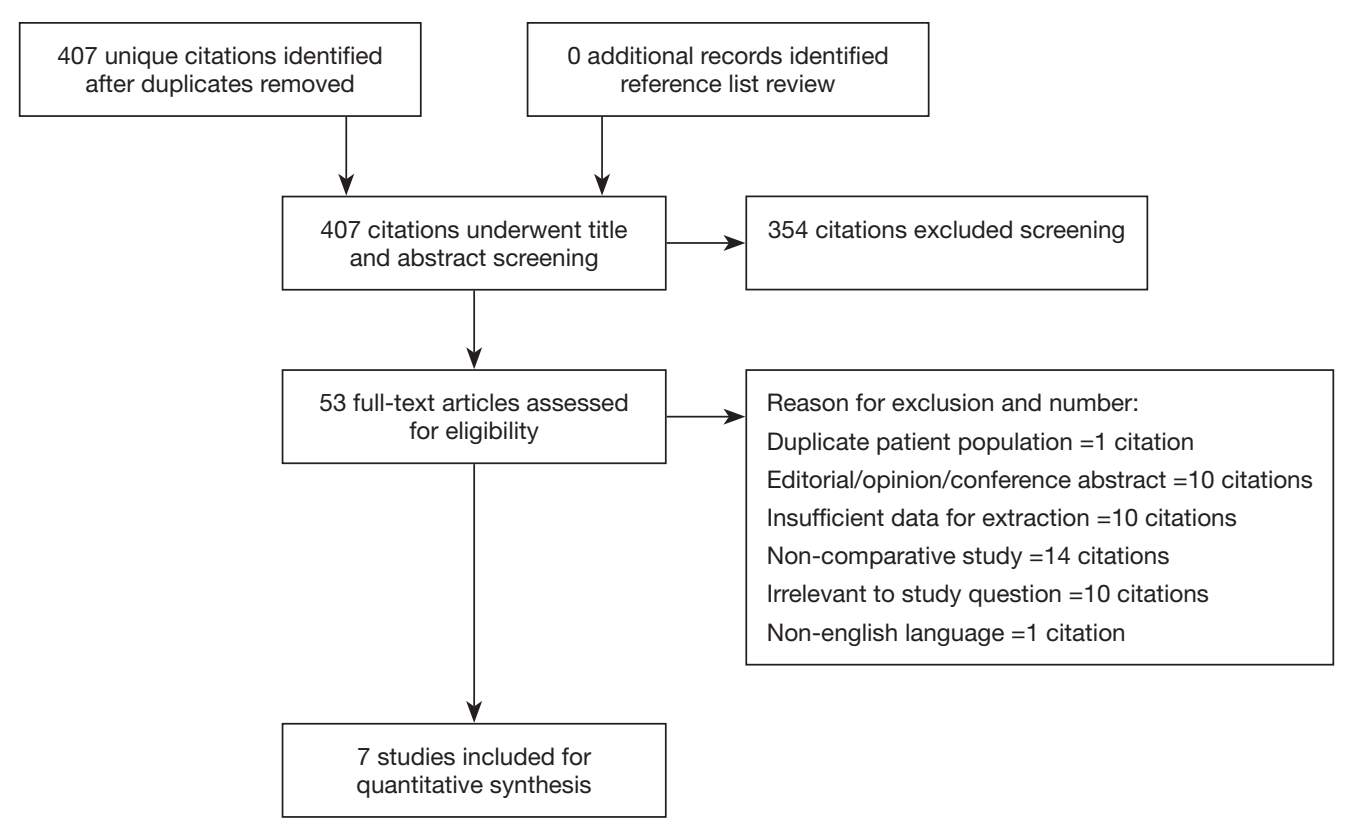

Figure S2 PRISMA diagram of study identification. PRISMA, the Preferred Reporting Items for Systematic Reviews and Meta-Analyses. 
Perceval Intuity Odds Ratio Study or Subgroup Events Total Events Total Weight $\mathbf{M - H}$, Random, 95\% Cl Beretta 2019

Chiariello 2019

D'Onofrio 2019

Ensminger 2018

Gotzmann 2019

Hartrumpf 2019

Liakopoulos 2018

Total $(95 \% \mathrm{Cl})$

Total events

Heterogeneity: $\mathrm{Tau}^{2}=0.00 ; \mathrm{Chi}^{2}=3.90, \mathrm{df}=6(\mathrm{P}=0.69) ; \mathrm{I}^{2}=0 \%$

Test for overall effect: $Z=0.00(P=1.00)$
$1.23[0.48,3.14]$

$3.26[0.32,33.61]$

$0.53[0.19,1.47]$

$1.08[0.54,2.17]$

$0.50[0.05,5.15]$

$0.48[0.03,7.90]$

$2.05[0.33,12.77]$

$1.00[0.64,1.57]$

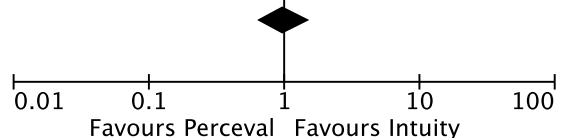

Figure S3 Forest plot of overall mortality.

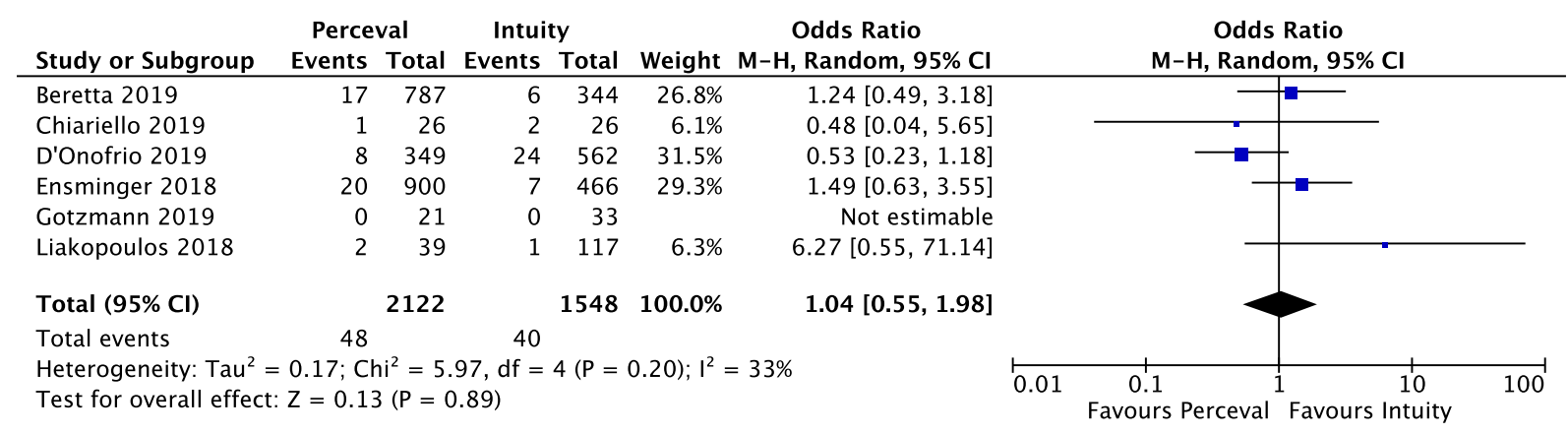

Figure S4 Forest plot of overall stroke rate.

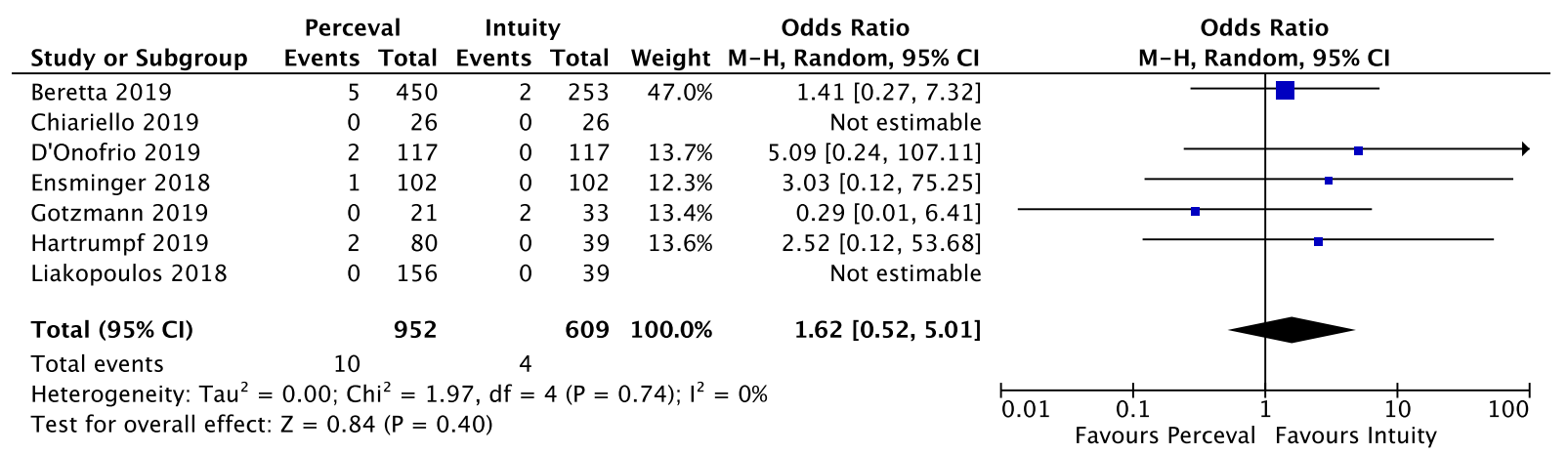

Figure S5 Forest plot of rate of post-operative moderate or worse paravalvular regurgitation using propensity matched pairs where available. 


\begin{tabular}{|c|c|c|c|c|c|c|c|c|c|c|}
\hline Study or Subgroup & \multicolumn{2}{|c|}{ Perceval } & \multicolumn{2}{|c|}{ Intuity } & Weight & Odds Ratio & \multicolumn{4}{|c|}{$\begin{array}{c}\text { Odds Ratio } \\
\mathrm{M}-\mathrm{H}, \text { Random, } 95 \% \mathrm{Cl}\end{array}$} \\
\hline Beretta 2019 & 31 & 450 & 12 & 253 & $37.1 \%$ & $1.49[0.75,2.95]$ & & & + & \\
\hline Chiariello 2019 & 0 & 26 & 0 & 26 & & Not estimable & & & & \\
\hline Ensminger 2018 & 89 & 900 & 13 & 466 & $41.8 \%$ & $3.82[2.11,6.92]$ & & & & \\
\hline Gotzmann 2019 & 3 & 21 & 3 & 33 & $11.2 \%$ & $1.67[0.30,9.16]$ & & & & \\
\hline Liakopoulos 2018 & 3 & 39 & 2 & 117 & $9.9 \%$ & $4.79[0.77,29.81]$ & & & & \\
\hline Total $(95 \% \mathrm{CI})$ & & 1436 & & 895 & $100.0 \%$ & $2.51[1.35,4.68]$ & & & & \\
\hline Total events & 126 & & 30 & & & & & & & \\
\hline $\begin{array}{l}\text { Heterogeneity: } \mathrm{Tau}^{2} \\
\text { Test for overall effec }\end{array}$ & $\begin{array}{l}0.15 ; C h \\
Z=2.89\end{array}$ & $\begin{array}{l}\mathrm{i}^{2}=4 \\
(\mathrm{P}=\end{array}$ & $\begin{array}{l}93, \mathrm{df}= \\
.004)\end{array}$ & $\partial T=$ & 18); I & $=39 \%$ & 0.01 & $\begin{array}{c}0.1 \\
\text { Favours Perceval }\end{array}$ & $\begin{array}{cc} & 10 \\
\text { Favours Intuity }\end{array}$ & 100 \\
\hline
\end{tabular}

Figure S6 Forest plot of the incidence of mild post-operative paravalvular regurgitation.

Perceval Intuity Odds Ratio

Study or Subgroup Events Total Events Total Weight $\mathrm{M}-\mathrm{H}$, Random, 95\% Cl

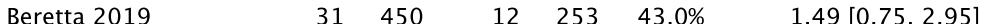

Chiariello 2019

Ensminger 2018

Gotzmann 2019

Liakopoulos 2018

Total $(95 \% \mathrm{Cl})$

Total events

Heterogeneity: $\mathrm{Tau}^{2}=0.36 ; \mathrm{Chi}^{2}=5.30, \mathrm{df}=3(\mathrm{P}=0.15) ; \mathrm{I}^{2}=43 \%$

Test for overall effect: $Z=2.20(P=0.03)$
$1.49[0.75,2.95]$

Not estimable

$8.62[1.92,38.76]$

$1.67[0.30,9.16]$

$4.79[0.77,29.81]$

$2.71[1.11,6.58]$

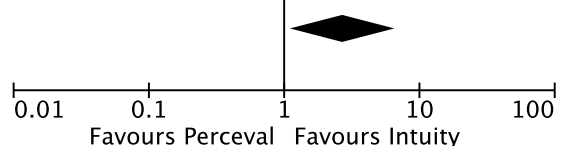

Figure S7 Forest plot of the incidence of mild post-operative paravalvular regurgitation using propensity matched pairs where available.

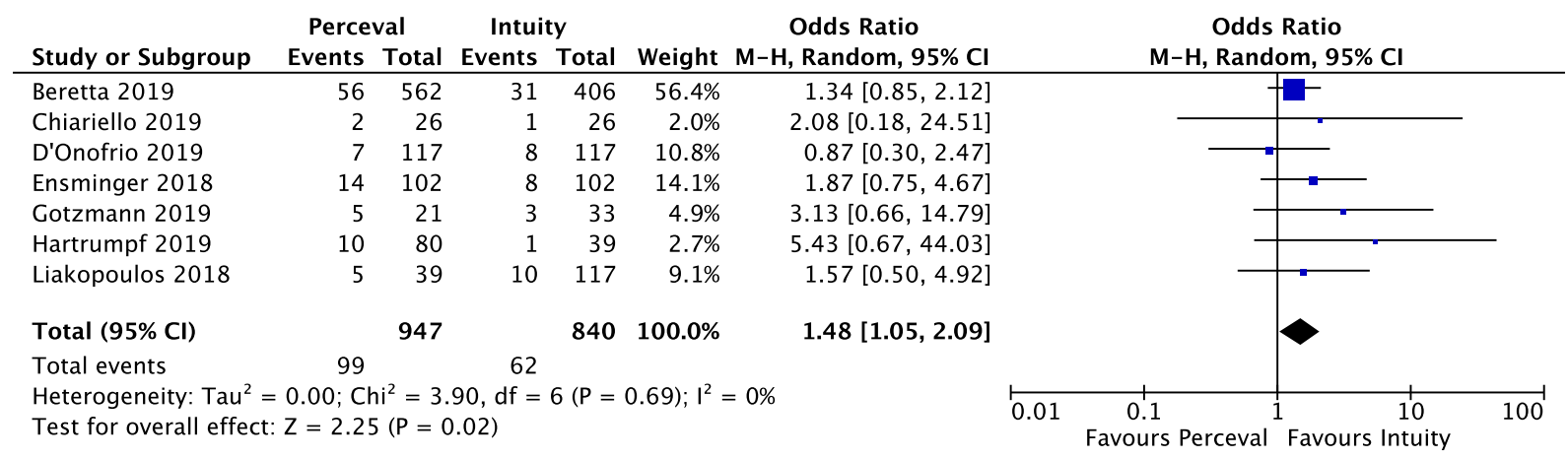

Figure S8 Forest plot of the rate of post-operative pacemaker implantation using propensity matched data where available.

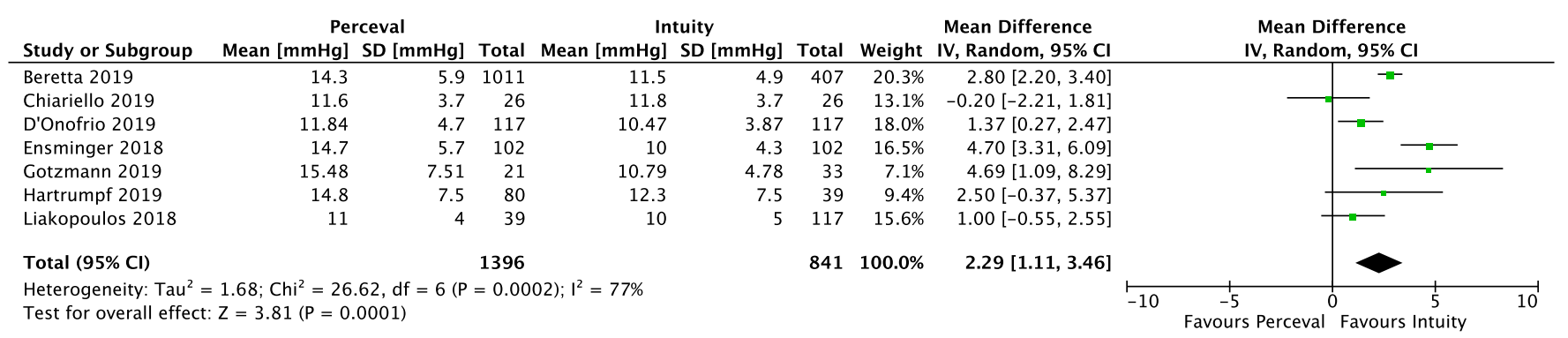

Figure S9 Forest plot of mean post-operative transvalvular gradient using propensity matched data where available. 


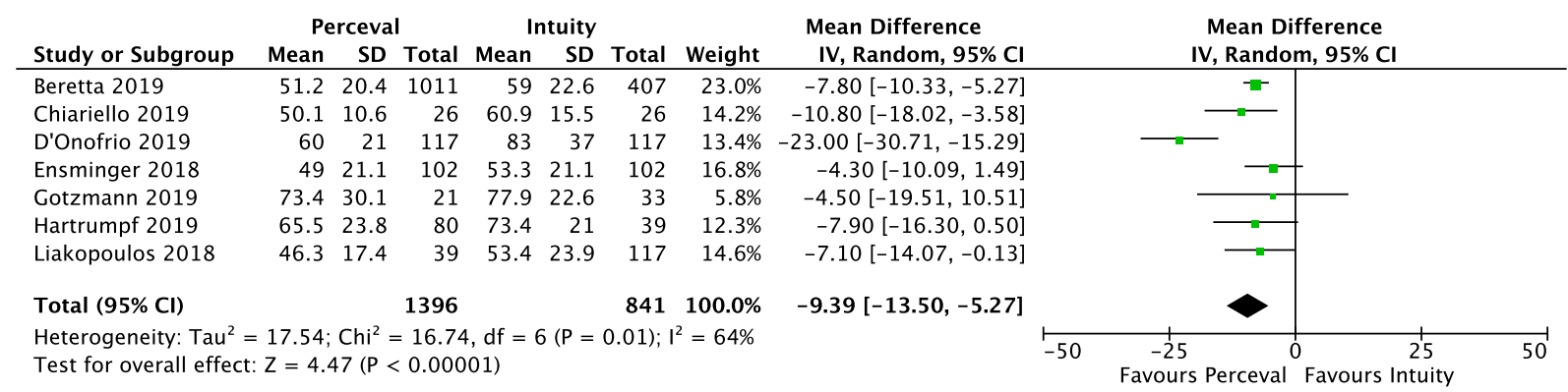

Figure S10 Forest plot comparing mean cross-clamp time using propensity matched data where available.

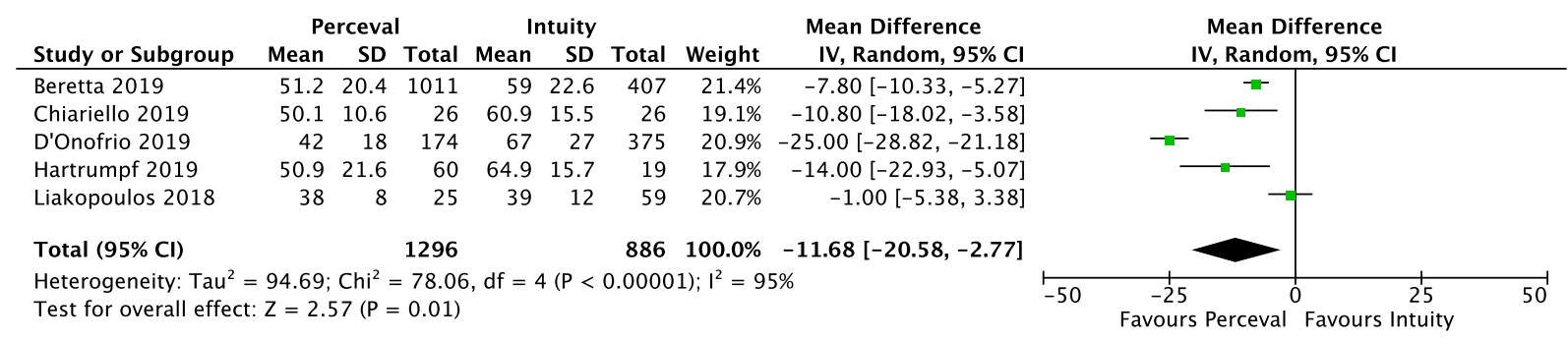

Figure S11 Forest plot comparing cross-clamp times for isolated aortic valve replacement.

\begin{tabular}{|c|c|c|c|c|c|c|c|c|c|c|c|}
\hline \multirow[b]{2}{*}{ Study or Subgroup } & \multicolumn{3}{|c|}{ Perceval } & \multicolumn{3}{|c|}{ Intuity } & \multirow[b]{2}{*}{ Weight } & \multirow{2}{*}{$\begin{array}{l}\text { Mean Difference } \\
\text { IV, Random, } 95 \% \mathrm{Cl}\end{array}$} & \multirow{2}{*}{\multicolumn{3}{|c|}{$\begin{array}{c}\text { Mean Difference } \\
\text { IV, Random, } 95 \% \mathrm{Cl}\end{array}$}} \\
\hline & Mean & SD & Total & Mean & SD & Total & & & & & \\
\hline Beretta 2019 & 81.2 & 28.9 & 1011 & 89.4 & 30.1 & 407 & $26.9 \%$ & $-8.20[-11.62,-4.78]$ & - & & \\
\hline Chiariello 2019 & 71.4 & 12.2 & 26 & 84.5 & 20.6 & 26 & $14.8 \%$ & $-13.10[-22.30,-3.90]$ & & & \\
\hline D'Onofrio 2019 & 90 & 32 & 117 & 112 & 48 & 117 & $12.8 \%$ & $-22.00[-32.45,-11.55]$ & & & \\
\hline Ensminger 2018 & 76.3 & 29.3 & 102 & 82.7 & 29.3 & 102 & $16.9 \%$ & $-6.40[-14.44,1.64]$ & & & \\
\hline Gotzmann 2019 & 94.3 & 38 & 21 & 98.8 & 26.8 & 33 & $5.6 \%$ & $-4.50[-23.15,14.15]$ & & & \\
\hline Hartrumpf 2019 & 90.3 & 36 & 80 & 113 & 29.5 & 39 & $10.6 \%$ & $-22.70[-34.86,-10.54]$ & & & \\
\hline Liakopoulos 2018 & 70.8 & 25.1 & 39 & 85.3 & 41.2 & 117 & $12.3 \%$ & $-14.50[-25.35,-3.65]$ & & & \\
\hline Total $(95 \% \mathrm{Cl})$ & & & 1396 & & & 841 & $100.0 \%$ & $-12.50[-17.39,-7.61]$ & & & \\
\hline \multicolumn{12}{|c|}{ 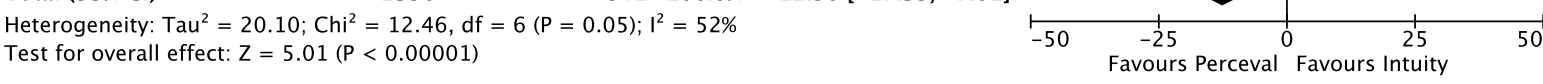 } \\
\hline
\end{tabular}

Figure S12 Forest plot comparing mean CPB time using propensity matched data where available. CPB, cardiopulmonary bypass.

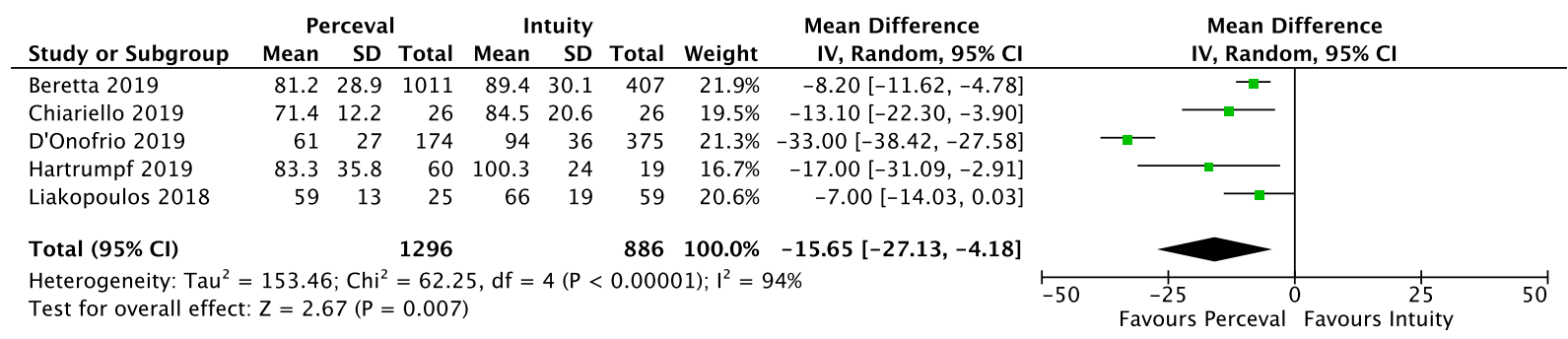

Figure S13 Forest plot comparing CPB times for isolated aortic valve replacement. CPB, cardiopulmonary bypass. 


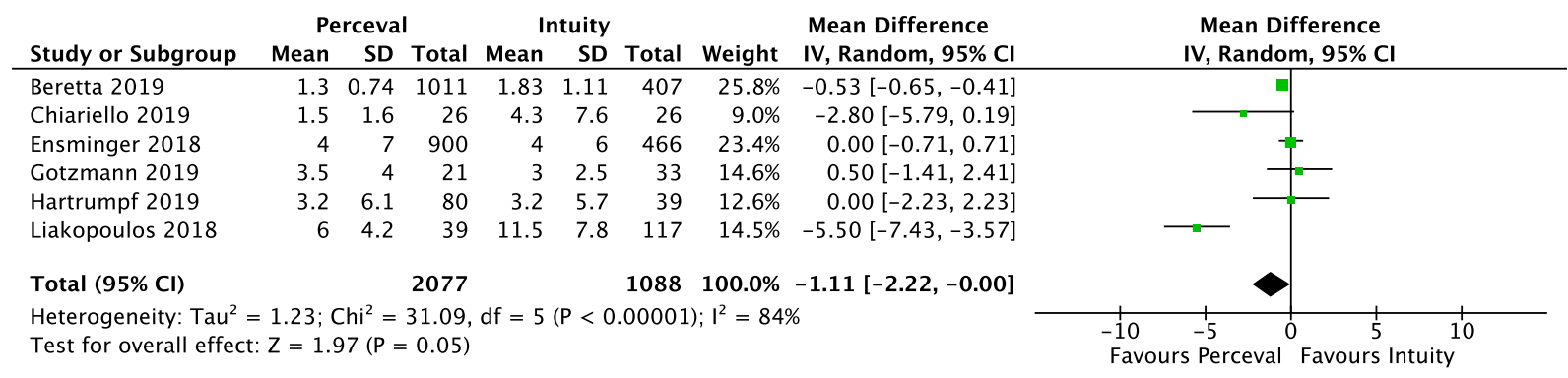

Figure S14 Forest plot comparing pooled mean intensive care unit length of stay (days).

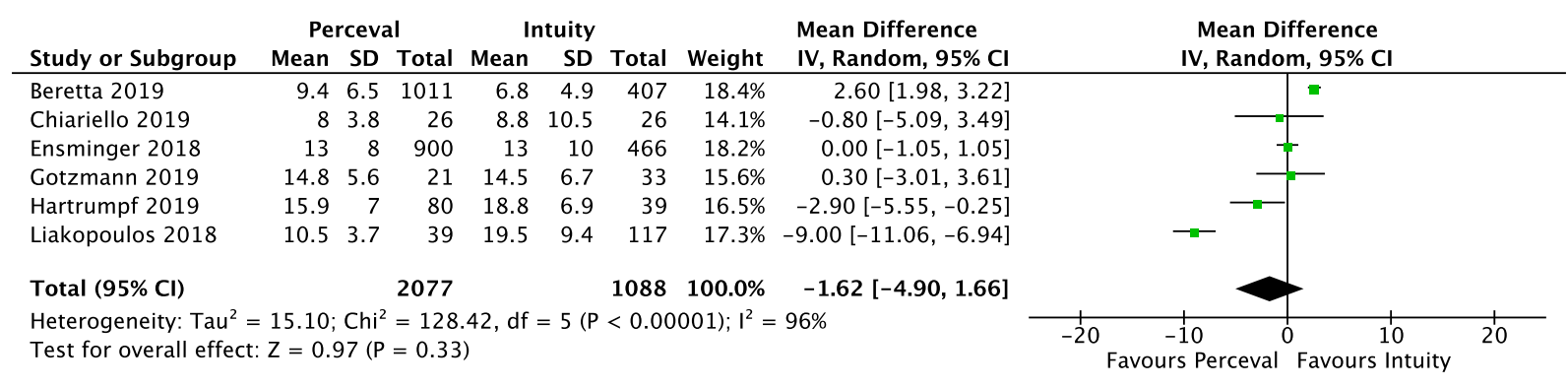

Figure S15 Forest plot comparing pooled mean hospital length of stay times (days). 